\title{
Zur Behandlung der Odontalgien in der Schwangerschaft.
}

\author{
Von \\ Dr. Isindner
}

in Waren.

Unter den Beschwerden, durch welche viele Schwangere aufs Aeusserste gequält und oft in ihrem Allgemeinbefinden erheblich gestört werden, nehmen wohl nächst dem Erbrechen die Odontalgien den ersten Platz ein. Dieselben erreichen oft solche Höhe, dass die betreffenden Schwangeren durch wochenlange Störung der Nachtruhe und durch die nie aussetzenden Schmerzen in besorguisserregender Weise herunterkommen. Die rationellste Behandlung bleibt ja nun immer die radicale durch Entfernung resp. sorgfältiges Plombiren der kranken Zähne, und ist wohl hentzutage das alte Vorurtheil gegen Zahnextractionen in der Gravidität bei den Aerzten ziemlicli ïberwunden. Ich habe als Assistent am Augusta-Hospitale in der Poliklinik eine grosse Zahl von Zahnextractionen bei Schwangeren ansgeführt, bis zu fünf hintereinander an derselben Frau, ohne den geringsten Nachtheil. Indess sieht man sich doch in vielen Fällen ausser Stande, die Radicaleur vorzunehmen, sei es, weil das Vorurtheil gegen Operationen an den Zähnen bei Schwangeren im Publikum noch zu mächtig ist, sei es, weil die Zahl der kranken Zähne eine so grosse ist, dass man selbst zu keinem Eingriffe rathen mag. In solchen Fällen bleibt man auf die symptomatische Behandlung mittels der verschiedenen Narcotica angewiesen, und bedient man sich zu diesem Zwecke vorwiegend des Morphium und Chloralhydrat. Dass man durch diese Mittel den Patientinnen grosse Erleichterung verschaffen und besonders anch durch Beseitigung der Schlaflosigkeit einen grossen Theil der ïblen Einwirkungen auf das Allgemeinbefinden heben kann, ist ja zweifellos, immerhin aber klebt doch denselben der grosse Nachtheil an, dass sie nur für wenige Stunden die Schmerzen hinwegnehmen, daher eine sehr häufige Anwendung nothwendig. machen, und - was besonders für arme Patientinnen sehr ins Gewicht fällt - während der Dauer ihrer Wirkung die Fran zur Arbeit mehr weniger unfähig machen. Ich habe mich nun in der letzten Zeit ausschliesslich des von Liebreich gegen Trigeminusneuralgien exapfoblenen Crotonchlowal bedient and bin mit demselben so ausserordentlich zufrieden, dass ich die Herren Collegen auf dieses Mittel nochmals aufmerksam machen und bitten möchte, in geeigneten Fällen dasselbe za versuchen. - Der Hauptvorzug des Crotonchloral besteht darin, dass die durch dasselbe erzielte Schmerzlosigkeit nicht in wenigen Stunden vorïbergeht, sondern mehrere Tage, bis zu acht 
Tagen, hintereinander anhält, dass daher eine viel seitenere Wiederholung nothwendig wird und dass die betreffenden Franen olne Beschwerden ihren Arbeiten nachgehen können.

Ich gebe das Mittel gewöhnlich Abends vor Schlafengehen nach folgender Formel:

Re Chloral. crotonisat. 0,6 . Aq. menth.

Syrup. menth. $\overline{\text { aa }} 15,0$.

M. D. S. Auf ein Mal in einem Glase Wein z. n.

Ueble Folgen habe ich weder bei den Schwangeren, noch bei anderen Patientinnen, bei denen ich das Mittel gegen heftige Zahnschmerzen gab, gesehen; in einem Falle trat Erbrechen auf, ohne dass die Wirkung dadurch gestört wurde. Dass das Mittel absolut nicht vertragen, sondern bei jedem Versuche, es zu nehmen, sofort wieder ausgebrochen wurde, sah ich nur bei zwei jungen Franen, Nichtschwangeren, doch glaube ich, dass in diesen beiden Fällen, die in einer Familie vorkamen, ein schlechtes Präparat die Schuld trägt, da ich sonst nichts dergleichen beobachtete. Zur Illustrirung meiner Angaben setze ich nachstehend einen besonders charakteristischen Fall bei, indem ich dazu bemerke, dass alle Fälle, die ich beobachtet, ähnlich verliefen:

Frau K., IVgravid., leidet seit mehreren Wochen an den heftigsten Zahnschmerzen, die die sonst sehr kräftige Frau aufs Aeusserste heruntergebracht haben. Da Patientin fast nur kranke Zähne hat, ist an eine Radicalcur nicht zu denken. Abends 0,6 Crotonchloral, eine Viertelstunde später Erbrechen, wonach Patientin einschlief. Ununterbrochener ruhiger Schlaf; am anderen Morgen erwacht Patientin vollkommen schmerzfrei und bleibt es fast acht Tage, trotzdem sie ihre Hausarbeiten in gewohnter Weise besorgt.

$\mathrm{Ob}$ das Crotonchloral in jedem Falle sich bewühren wird, lässt sich natürlich mit Sicherheit nicht sagen, immerhin scheint mir ein Versuch damit nach meinen bisherigen Erfahrungen wohl motivirt. 